\title{
Liver function, quantified by the LiMAx test, as a predictor for the clinical outcome of critically ill patients treated with linezolid
}

\author{
Rawan Alraish ${ }^{\mathrm{a}, *}$, Sebastian G. Wicha ${ }^{\mathrm{b}}$, Otto R. Frey ${ }^{\mathrm{c}}$, Anka C. Roehr ${ }^{\mathrm{c}}$, Johann Pratschke ${ }^{\mathrm{a}}$, \\ Martin Stockmann ${ }^{\mathrm{a}}$, Tilo Wuensch ${ }^{\mathrm{a}}$ and Magnus Kaffarnik ${ }^{\mathrm{a}}$ \\ ${ }^{a}$ Department of Surgery, Campus Charité Mitte/Campus Virchow-Klinikum, Charité - \\ Universitätsmedizin Berlin, 13353 Berlin, Germany \\ ${ }^{\mathrm{b}}$ Department of Clinical Pharmacy, Institute of Pharmacy, University of Hamburg, 20146 Hamburg, \\ Germany \\ ${ }^{\mathrm{C}}$ Clinical Pharmacy, Klinikum Heidenheim, 89522 Heidenheim, Germany
}

Received 28 June 2019

Accepted 24 February 2021

\begin{abstract}
.
BACKGROUND: Critically ill patients commonly suffer from infections that require antimicrobial therapy. In previous studies, liver dysfunction was shown to have an essential impact on the dose selection in these patients. This pilot study aims to assess the influence of liver dysfunction, measured by the novel LiMAx test, on clinical outcomes in critically ill patients treated with linezolid.

METHODS: Twenty-nine critically ill patients were included and treated with linezolid. Indications for linezolid therapy were secondary or tertiary peritonitis (46.7\%), bloodstream infection $(6.7 \%)$ and $46.7 \%$ were other infections with gram-positive bacteria. Linezolid $\mathrm{C}_{\min }$, maximal liver function capacity (LiMAx test) and plasma samples were collected while linezolid therapy was in a steady-state condition. Furthermore, potential factors for the clinical outcome were investigated using logistic regression analysis. Clinical cure was defined as the resolution or significant improvement of clinical symptoms without using additional antibiotic therapy or intervention.

RESULTS: Cured patients presented lower median linezolid $\mathrm{C}_{\min }$ yet a significantly higher mean LiMAx-value compared to the clinical failure group $(1.9 \mathrm{mg} / \mathrm{L}$ vs. $5.1 \mathrm{mg} / \mathrm{L})(349 \mu \mathrm{g} / \mathrm{kg} / \mathrm{h}$ vs. $131 \mu \mathrm{g} / \mathrm{kg} / \mathrm{h})$. In the logistic regression model, LiMAx $<178 \mu \mathrm{g} / \mathrm{kg} / \mathrm{h}$ was the only independent predictor of clinical failure with a sensitivity of $77 \%$ and specificity of $93 \%$.

CONCLUSIONS: The LiMAx test predicts clinical failure more precisely than linezolid trough levels in critically ill surgical patients. Therefore liver failure may have a stronger impact on the outcome of critically ill surgical patients than low linezolid $\mathrm{C}_{\min }$. While linezolid $\mathrm{C}_{\min }$ failed to predict patient's outcome, LiMAx results were the only independent predictor of clinical failure.
\end{abstract}

Keywords: Linezolid, dosage, liver function test, clinical outcome

\section{Introduction}

Patients from the intensive care unit (ICU) frequently suffer from bacterial infections resulting in high

\footnotetext{
${ }^{*}$ Corresponding author: Rawan Alraish, Department of Surgery, Campus Charité Mitte/Campus Virchow-Klinikum, Charité Universitätsmedizin Berlin, Augustenburger Platz 1, 13353 Berlin, Germany. E-mail: rawan.alraish@charite.de.
}

0928-7329 (c) 2022 - The authors. Published by IOS Press. This is an Open Access article distributed under the terms of the Creative Commons Attribution-NonCommercial License (CC BY-NC 4.0). 
mortality rates between $20 \%$ to $50 \%$ [1-5]. Thus, finding the optimal antimicrobial therapy with an appropriate dosage regime in ICU patients is of the utmost necessity to achieve a fast treatment response with high success rates.

Linezolid, an oxazolidinone antibiotic, remains an essential antimicrobial agent against most grampositive bacteria, including resistant strains, which are particularly frequent in intensive care units [6-10]. While reasonable data regarding a successful therapy with linezolid were obtained in less severely ill patients, clinical observations in ICU patients have shown treatment failure by up to $30 \%$. Further, $15 \%$ to $30 \%$ of critically ill patients receiving linezolid, have suffered from adverse effects (e.g., elevated liver enzymes, gastrointestinal disturbances, haematological toxicity) [11-13].

Linezolid is metabolised non-enzymatically and enzymatically by liver enzymes into two major inactive metabolites [14,15]. The clearance of linezolid is approximately $65 \%$ non-renal, with up to $30 \%$ excreted unchanged in the urine [15]. Based on these data, a high variability of linezolid in patients with hepatic impairment is not expected. However, some studies showed a wide interindividual variability of linezolid plasma concentrations during treatment with the recommended flat dosing of $600 \mathrm{mg}$ twice daily $[11,16]$. Moreover, patients with liver dysfunction are reported to have a significantly higher risk of developing side effects, which could contribute to inadequate antimicrobial treatment [17].

The role of the liver as a modulator of drug-pharmacokinetics is well known. Some previous studies reported an alteration in serum trough concentrations of antibiotics in patients suffering from liver dysfunction [18-20]. Due to the lack of reliable liver function tests, no existing data can describe the impact of the degree of liver function on the pharmacokinetics of linezolid and the patient's clinical outcome. In a recent pilot study, we demonstrated pharmacokinetic variability in linezolid serum concentrations depending on hepatic function using the maximal liver function capacity (LiMAx test) [21]. Patients with LiMAx values in the normal range showed significantly lower linezolid serum concentration. In this prospective observational study, we therefore aim to evaluate the clinical outcome of critically ill patients treated with linezolid depending on the hepatic function. Furthermore, potential factors predicting the outcome of these patients were investigated using a logistic regression model.

\section{Methods}

\subsection{Study design}

The study was approved by the ethics review board of the Charite medical faculty in accordance with the provisions of the Declaration of Helsinki. Written informed consent was obtained from all participants or their responsible legal representatives prior to study inclusion (ethics board approval number EA4/022/13).

Patients from the surgical intensive care unit (SICU) of the Charite University Hospital were included in the study. Inclusion criteria were a medical indication (proven infection with suspected or proven involvement of gram-positive bacteria) for intravenous anti-infective therapy with linezolid and an age between 18 and 99 years. Exclusion criteria were an allergy against linezolid or methacetin, co-medication with substances metabolized by cytochrome P450 1A2 or with substances affecting the clearance of linezolid and missing informed consent.

Included patients $(n=29)$ were treated with the recommended standard dosing of $600 \mathrm{mg}$ linezolid twice a day by an infusion duration of $30 \mathrm{~min}$. In order to measure linezolid $\mathrm{C}_{\min }$ in a steady state condition, the day of measurement and probe sampling was carried out $\geqslant 36$ and $<72$ hours after the first dosage of the drug. On the same day, a LiMAx test was performed, a serum sample, a 24-hours urine 
sample and a dialysate sample in patients on continuous venovenous hemodialysis were taken and routine blood parameters were measured. The serum sample was obtained from a $10 \mathrm{~mL}$ blood sample drawn from a central venous or arterial line 15 min prior to administration of the next linezolid dose. Serum aliquots were stored at $-80^{\circ} \mathrm{C}$ after centrifugation at $4000 \mathrm{rpm}$ for $5 \mathrm{~min}$ within one hour after blood sampling. Serum linezolid concentrations were determined using a previously described high-performance liquid chromatography method (HPLC) [22]. The target concentration range for linezolid $\mathrm{C}_{\min }$ was defined according to recently published findings. The lower threshold of the target concentration range was set as $2 \mathrm{mg} / \mathrm{L}$ and the upper threshold was set at $8 \mathrm{mg} / \mathrm{L}[11,16]$. Biochemical parameter of the liver function such as aspartate aminotransferase (AST), alanine aminotransferase (ALT), gamma-glutamyl transferase (GGT), pseudocholinesterase (PCHE), glutamate dehydrogenase (GLDH), total bilirubin, lactate, platelets count and international normalized ratio (INR) were evaluated at the beginning of the therapy as a baseline and on the day of measurement. Patients' severity of illness was investigated using the Acute Physiology and Chronic Health Evaluation (APACHE II) score [23], the Sepsis Organ Failure Assessment (SOFA) score [24], the Simplified Acute Physiology Score II (SAPS II) [25] and Model for End-Stage Liver Disease (MELD) [26,27]. Demographic and clinical characteristics presumably affecting linezolid therapy such as age, sex, Body mass index (BMI), creatinine clearance $\left(\mathrm{CL}_{\mathrm{CR}}=\left(\mathrm{C}_{\text {urine }} * \mathrm{~V}_{\text {urine }}\right): \mathrm{C}_{\text {serum }}\right.$ corrected according to the body surface area obtained from the height and weight of the patient) and albumin level score were investigated.

\section{2. $\operatorname{LiMAx}$}

The LiMAx test was performed using the FLIP ${ }^{\mathrm{TM}}$ Analyzer (Humedics GmbH, Berlin, Germany). ${ }^{13} \mathrm{C}$ labelled methacetin was injected intravenously $(2 \mathrm{mg} / \mathrm{kg}$ body weight). The substrate was metabolized by the liver enzyme cytochrome P450 $1 \mathrm{~A} 2$ into acetaminophen and ${ }^{13} \mathrm{C}$-labelled $\mathrm{C}$, which was then transported into the lungs and exhaled as ${ }^{13} \mathrm{CO}_{2}$. From the exhaled breath, a baseline of the patient's individual ${ }^{13} \mathrm{CO}_{2} /{ }^{12} \mathrm{CO}_{2}$ ratio was detected and the Liver function capacity was calculated from the kinetic analysis of ${ }^{13} \mathrm{CO}_{2}:{ }^{12} \mathrm{CO}_{2}$ ratio over a period of 60 minutes. The normal range was defined as $>$ $31 \mu \mathrm{g} / \mathrm{kg} / \mathrm{h}[28,29]$.

\subsection{Determination of clinical outcome}

Clinical outcome was assessed until seven days after the end of therapy. Clinical cure was defined as the resolution or significant improvement of clinical symptoms evaluated by an intensivist compared to the beginning of therapy such that no additional antibiotic therapy or intervention was necessary [30,31]. Clinical failure was defined as death due to treated infection, persistence or recurrence of infection during linezolid therapy (inadequate response) and new or persistent symptoms at least 7 days after the end of therapy. The need for a change in antibiotic therapy due to adverse effects or clinical worsening and a positive culture for gram-positive bacteria at the site of primary infection reported at the end of therapy was also considered a clinical failure [32]. An uncertain outcome was recorded when there was insufficient information available to determine the outcome or the patient died from causes other than an infection.

\subsection{Statistical analysis}

Patients were divided into two groups determined by their clinical outcome. Continuous variables are shown as the median and interquartile range. Categorical variables were investigated with Fisher's exact test and are shown as frequencies. Depending on the distribution, tested by the Kolmogorov-Smirnov 
test in combination with the Shapiro-Wilk test, comparisons between clinical failure and clinical cure were performed using the Mann-Whitney $\mathrm{U}$ test or the independent ttest for non-connected samples. A $P$-value of $<0.05$ was considered statistically significant.

Variables related to the clinical outcome were analyzed by univariate analysis using Pearson's chisquared test. Multivariable logistic regression was performed on candidate predictor variables to identify independent risk factors for clinical cure. The receiver operating characteristic (ROC) curve was applied to calculate the best cut-off value of minimum LiMAx during linezolid therapy for the prediction of clinical outcome. Further ROC-curve analysis was performed on Bilirubin, Platelet count and INR in order to compare it with the LiMAx ROC-curve. Statistical analysis was performed with SPSS Statistics 22 (SPSS Inc., Chicago, IL, USA).

\section{Results}

\subsection{Demographic and characteristics of patient groups}

A total of twenty-nine patients were observed in our clinical study. Twenty-eight patients were divided into two arms according to their evaluated clinical outcome. One remaining male patient (age 61 years) was documented as the indeterminate response due to death from reasons outside of infection. Fifteen patients were cured of the infection (11 males, 4 females, median age 57 years) and therefore included in the clinical cure group. Thirteen patients ( 7 males, 6 females, median age 71 years) showed a treatment failure and were included in the clinical failure group. In almost $47 \%$ of the patients, the indication of linezolid therapy was secondary or tertiary peritonitis, in nearly $7 \%$ a bloodstream infection and in the rest of the patient' other source of infection was detected (46.7\%). Gram-positive bacteria were observed in $89.3 \%$ of the patients, while in $28.6 \%$ of all cases a co-infection with multidrug-resistant gram-negative bacteria (MRGN) was observed (Table 1).

No significant differences were observed between the two groups at the beginning of therapy regarding disease severity (SOFA-, SAPSII-, APACHEII score), gamma-glutamyl transferase (GGT), white blood cells count (WBC), platelet counts and serum creatinine. Patients with clinical failure showed significantly higher values for age, lactate, total bilirubin, aspartate aminotransferase (AST), alanine aminotransferase (ALT) and MELD score. The baseline characteristics of both groups are shown in Table 1.

\subsection{Comparisons of liver function and linezolid serum concentration depending on the clinical outcome}

Patients with clinical cure had a mean LiMAx-value of $349 \mu \mathrm{g} / \mathrm{kg} / \mathrm{h}$ (normal range $>315 \mu \mathrm{g} / \mathrm{kg} / \mathrm{h}$ ). LiMAx-values in the clinical failure group were significantly lower with a mean value of $131 \mu \mathrm{g} / \mathrm{kg} / \mathrm{h}$ $(p<0.01)$. Platelet counts, lactate blood levels, INR and total bilirubin, showed a significant difference between the two arms with higher values in the clinical failure group $(p<0.001)$. AST $(p=0.062)$, ALT $(p=0.146)$, GGT $(p=0.928)$, PCHE $(p=0.247)$ and GLDH $(p=0.096)$ were not significantly different in the two groups. Mean $\mathrm{CL}_{\mathrm{CR}}$ in the clinical cure group was significantly higher than in the clinical failure group ( $87.3 \mathrm{~mL} / \mathrm{min}$ vs. $29.4 \mathrm{~mL} / \mathrm{min}, p=0.006$ ) (Table 2 ).

The median linezolid $\mathrm{C}_{\min }$ in the clinical cure group was lower compared to the clinical failure group $\left(1.9 \mathrm{mg} / \mathrm{L}\right.$ vs. $5.1 \mathrm{mg} / \mathrm{L}, \mathrm{n}$. s.). Whilst median $\mathrm{C}_{\min }$ in the clinical cure group was under the lower range, median $\mathrm{C}_{\min }$ in the clinical failure group remained within the therapeutic range $(2 \mathrm{mg} / \mathrm{L}-8 \mathrm{mg} / \mathrm{L})$. In the clinical cure group, $54 \%$ of linezolid $\mathrm{C}_{\min }$ was found outside the therapeutic range $(47 \%<2 \mathrm{mg} / \mathrm{L}$ and $7 \%>8 \mathrm{mg} / \mathrm{L}$ ). In the clinical failure arm, $60 \%$ of linezolid $\mathrm{C}_{\min }$ was found outside the therapeutic range $(30 \%>8 \mathrm{mg} / \mathrm{L}$ and $30 \%<2 \mathrm{mg} / \mathrm{L})$ (Fig. 1$)$. 
Table 1

Baseline characteristics before start of linezolid therapy

\begin{tabular}{|c|c|c|c|}
\hline & Clinical cure & Clinical failure & $P^{\mathrm{a}, \mathrm{b}, \mathrm{c}}$ \\
\hline Patients $(n)$ & 15 & 13 & \\
\hline Age (y) & $57(50-62)$ & $71(63.0-80.5)$ & $0.004^{\mathrm{c}}$ \\
\hline Gender (m/f) & $11 / 4$ & $7 / 6$ & $0.433^{\mathrm{b}}$ \\
\hline BMI $\left(\mathrm{kg} / \mathrm{m}^{2}\right)$ & $24.2(20.3-27.8)$ & $26.8(24.4-30.5)$ & $0.442^{\mathrm{c}}$ \\
\hline Lactate $(\mathrm{mmol} / \mathrm{L})$ & $0.92(0.67-1.29)$ & $2.11(1.27-3.50)$ & $0.019^{\mathrm{c}}$ \\
\hline INR & $1.37(1.20-1.43)$ & $1.37(1.24-1.99)$ & $0.060^{\mathrm{c}}$ \\
\hline Total bilirubin (mmol/L) & $0.03(0.01-0.06)$ & $0.17(0.05-0.36)$ & $0.002^{\mathrm{a}}$ \\
\hline Platelet counts $(/ \mathrm{nL})$ & $254.0(202.0-369.0)$ & $103.0(43.5-311.0)$ & $0.072^{\mathrm{c}}$ \\
\hline AST (IU/L) & $36.0(30.0-64.0)$ & $85.0(56.5-215.5)$ & $0.006^{\mathrm{a}}$ \\
\hline ALT (IU/L) & $25.0(17.0-36.5)$ & $39.0(28.5-139.0)$ & $0.043^{\mathrm{a}}$ \\
\hline GGT (IU/L) & $152.0(29.0-328.0)$ & $120.0(54.5-267.0)$ & $0.964^{\mathrm{a}}$ \\
\hline WBC (/nL) & $16.01(9.34-26.10)$ & $17.67(11.17-31.45)$ & $0.464^{\mathrm{c}}$ \\
\hline $\mathrm{CRP}(\mathrm{mmol} / \mathrm{L})$ & $7.72(5.22-14.87)$ & $11.25(3.34-12.30)$ & $0.418^{\mathrm{a}}$ \\
\hline Serum creatinine (mmol/L) & $0.04(0.03-0.07)$ & $0.08(0.05-0.14)$ & $0.280^{\mathrm{c}}$ \\
\hline MELD-score & $13(9-16)$ & $24(10-30)$ & $0.017^{\mathrm{c}}$ \\
\hline SOFA score & $12(8-12)$ & $11(8-16)$ & $0.519^{\mathrm{a}}$ \\
\hline SAPS II score & $70(37-78)$ & $69(58-85)$ & $0.350^{\mathrm{a}}$ \\
\hline APACHE II score & $32(19-33)$ & $28(26-37)$ & $0.519^{\mathrm{a}}$ \\
\hline \multicolumn{4}{|l|}{ Indication for linezolid, $n$ (\%) } \\
\hline Secondary peritonitis & $6(40)$ & $5(38.5)$ & $>0.99$ \\
\hline Tertiary peritonitis & $1(6.7)$ & $3(23.1)$ & 0.625 \\
\hline Blood stream infection & $1(6.7)$ & $1(7.7)$ & $>0.99$ \\
\hline Other & 7 (46.7) & $4(30.7)$ & 0.549 \\
\hline \multicolumn{4}{|l|}{ Microbiological isolate, $n(\%)$} \\
\hline Enterococcus faecalis & $2(13)$ & $2(15.4)$ & $>0.99$ \\
\hline Enterococcus faecium & $1(6.7)$ & $1(7.7)$ & $>0.99$ \\
\hline Gemella sp, & $1(6.7)$ & $0(0)$ & $>0.99$ \\
\hline Lactococcus lactis & $1(6.7)$ & $0(0)$ & $>0.99$ \\
\hline$M R S A$ & $0(0)$ & $1(7.7)$ & $>0.99$ \\
\hline Staphylococcus epidermidis & $2(13)$ & $0(0)$ & 0.500 \\
\hline Streptococcus mitis & $2(13)$ & $0(0)$ & 0.500 \\
\hline Streptococcus salivarius & $2(13)$ & $0(0)$ & 0.500 \\
\hline$V R E$ & $2(13)$ & $8(61.5)$ & 0.109 \\
\hline$M D R G N$ & $5(33)$ & $3(23.1)$ & 0.727 \\
\hline \multicolumn{4}{|l|}{ Co-treatment, $n(\%)$} \\
\hline Colistin & $0(0)$ & $1(7.7)$ & $>0.99$ \\
\hline Meropenem & $15(100)$ & $13(100)$ & $>0.99$ \\
\hline Tobramycin & $0(0)$ & $1(7.7)$ & $>0.99$ \\
\hline
\end{tabular}

Data are presented as median and interquartile range (25th to 75 th percentile) or frequencies. BMI: Body mass index; INR: International normalized ratio; AST: Aspartate aminotransferase; ALT: Alanine aminotransferase; GGT: Gamma-glutamyl transferase; WBC: White blood cell count; CRP: C-reactive protein; MELD: Model for end-stage liver disease; SOFA: Sequential organ failure assessment; SAPS: Simplified acute physiology score; APACHE II: Acute physiology and chronic health evaluation; MRSA: Methicillin-resistant staphylococcus aureus; VRE: Vancomycin-resistant enterococci; MDRGN: Multidrug-resistant gramnegative bacteria.

${ }^{\mathrm{a}}$ Mann-Whitney-U-test; ${ }^{\mathrm{b}}$ Fisher's-exact-test; ${ }^{\mathrm{c}}$ Independent- $t$-test.

\subsection{Independent predictors of clinical deterioration}

The univariate analysis showed that LiMAx-value $(p<0.01)$, creatinine clearance $(p<0.01)$, platelet counts $(p<0.01)$, lactate $(p<0.01)$, total bilirubin $(p=0.03)$ and linezolid $\mathrm{C}_{\min }(p=0.03)$ were associated with the clinical outcome of the patient cohort (Table 3 ). The correlated matrix of potential predictors was examined to ensure that there was no collinearity of independent variables within each 
Table 2

Comparisons between patients with clinical cure and clinical failure $\geqslant 36$ and $<72$ after beginning of linezolid therapy

\begin{tabular}{lllc}
\hline & Clinical cure $(n=15)$ & Clinical failure $(n=13)$ & $P^{\mathrm{a}, \mathrm{b}}$ \\
\hline LiMAx $(\mu \mathrm{g} / \mathrm{kg} / \mathrm{h})$ & $326(204-444)$ & $131(60-190)$ & $0.000^{\mathrm{b}}$ \\
Lactate $(\mathrm{mmol} / \mathrm{L})$ & $0.67(0.50-0.94)$ & $1.67(0.94-3.44)$ & $0.000^{\mathrm{b}}$ \\
INR & $1.25(1.14-1.35)$ & $1.39(1.22-1.94)$ & $0.043^{\mathrm{b}}$ \\
Total bilirubin $(\mathrm{mmol} / \mathrm{L})$ & $0.03(0.02-0.04)$ & $0.23(0.07-0.38)$ & $0.003^{\mathrm{a}}$ \\
Platelet count $(/ \mathrm{nL})$ & $219(168-274)$ & $72(33-175)$ & $0.001^{\mathrm{b}}$ \\
AST (IU/L) & $52(27-88)$ & $102(47-304)$ & $0.062^{\mathrm{a}}$ \\
ALT (IU/L) & $27(19-67)$ & $45(24-143)$ & $0.146^{\mathrm{a}}$ \\
GGT $(\mathrm{IU} / \mathrm{L})$ & $218(48-511)$ & $283(53-346)$ & $0.928^{\mathrm{a}}$ \\
PCHE $(\mathrm{kU} / \mathrm{L})$ & $2.5(1.7-2.8)$ & $2.6(1.6-3.9)$ & $0.247^{\mathrm{b}}$ \\
GLDH (IU/L) & $8.1(3.8-26.8)$ & $24.4(6.6-124.4)$ & $0.096^{\mathrm{b}}$ \\
MELD-score & $10(9-17)$ & $28(10-33)$ & $0.046^{\mathrm{a}}$ \\
Linezolid $C_{\text {min }}(\mathrm{mg} / \mathrm{L})$ & $1.9(0.5-3.9)$ & $5.1(1.8-9.1)$ & $0.720^{\mathrm{b}}$ \\
Creatinine clearance $(\mathrm{mL} / \mathrm{min})$ & $86.40(38.70-114.20)$ & $11.50(1.85-42.00)$ & $0.006^{\mathrm{b}}$ \\
Duration of therapy (days) & $10(7-14)$ & $10(9-14)$ & $0.677^{\mathrm{b}}$ \\
SOFA score & $14(12-19)$ & $14(10-18)$ & $0.767^{\mathrm{a}}$ \\
SAPS score & $80(68-95)$ & $79(68-92)$ & $1.000^{\mathrm{a}}$ \\
\hline
\end{tabular}

Data are presented as median and interquartile range (25th to 75th percentile). LiMAx: Maximal liver function capacity; INR: International normalized ratio; AST: Aspartate aminotransferase; ALT: Alanine aminotransferase; GGT: Gammaglutamyl transferase; PCHE: Pseudocholinesterase; GLDH: Glutamate dehydrogenase; MELD: Model for end-stage liver disease; SOFA: Sequential organ failure assessment; SAPS: Simplified acute physiology score. ${ }^{\text {a }}$ Mann-Whitney-U-test, ${ }^{\text {Independent- }}$ $t$-test.

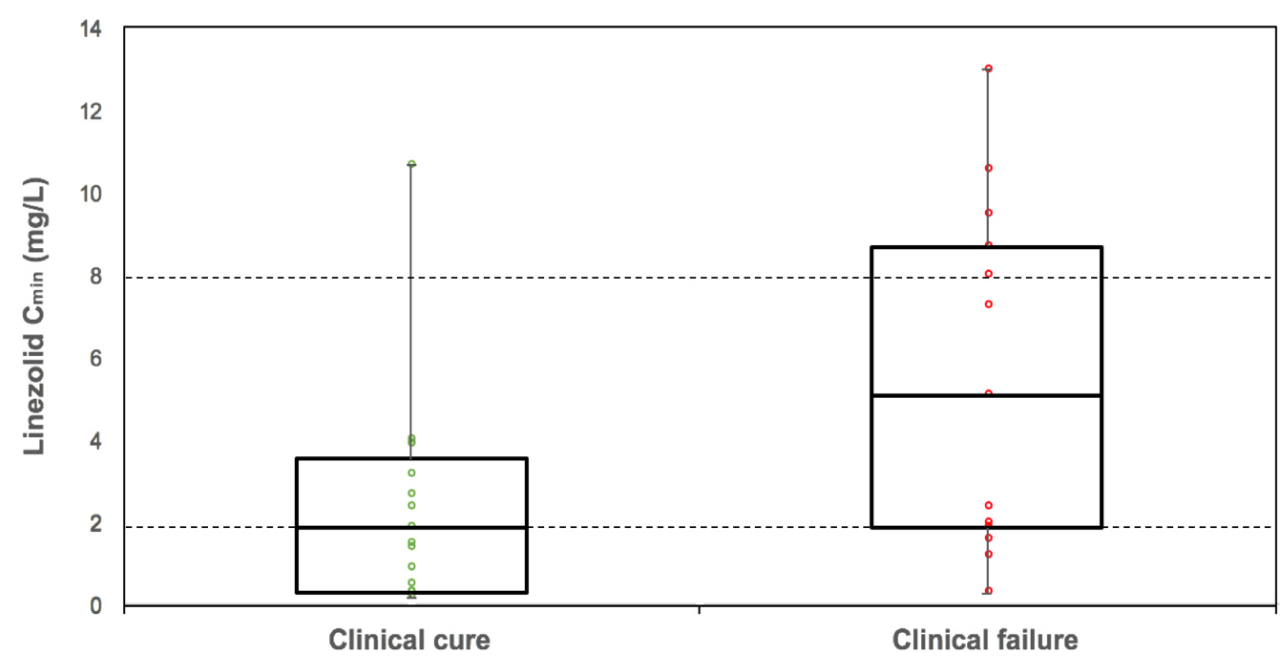

Fig. 1. Linezolid serum trough concentration depending on clinical outcome. Data are presented as box-and-whisker plots showing median with interquartile range. Linezolid overlaid with dot plot of the linezolid trough serum concentration of each patient belong to each group. Dotted lines define the lower and upper plasma target range.

other. Variables and interaction terms were analyzed in the multivariable binary logistic regression using the stepwise method.

The final multivariable binary logistic regression model found only the LiMAx test as an independent predictor of clinical cure (Table 3). The Omnibus tests of model coefficients indicated that this model was 
Table 3

Predictors associated with clinical outcome

\begin{tabular}{lccccc}
\hline & Univariate analysis & \multicolumn{3}{c}{ Multivariate analysis } \\
\cline { 2 - 4 } & Sig. & OR & \multicolumn{2}{c}{ CI 95\% } & Sig. \\
\cline { 2 - 4 } & & & Upper & Lower & \\
\hline Linezolid $\mathrm{C}_{\min }(\mathrm{mg} / \mathrm{L})$ & 0.03 & 1.022 & 1.003 & 1.042 & 0.025 \\
LiMAx value $(\mu \mathrm{g} / \mathrm{kg} / \mathrm{h})$ & $<0.01$ & & & & \\
Platelet count $(\mathrm{cells} / \mathrm{nL})$ & $<0.01$ & & & & \\
Lactate $(\mathrm{mg} / \mathrm{dL})$ & $<0.01$ & & & & \\
Billirubin $(\mathrm{mg} / \mathrm{dL})$ & 0.03 & & & & \\
INR & 0.03 & & & & \\
$\mathrm{Cl}_{\mathrm{Cr}}(\mathrm{mL} / \mathrm{min})$ & $<0.01$ & & & & \\
\hline
\end{tabular}

LiMAx: Maximal liver function capacity; INR: International normalized ratio; $\mathrm{Cl}_{\mathrm{Cr}}$ : Creatinine clearance.

LiMAx

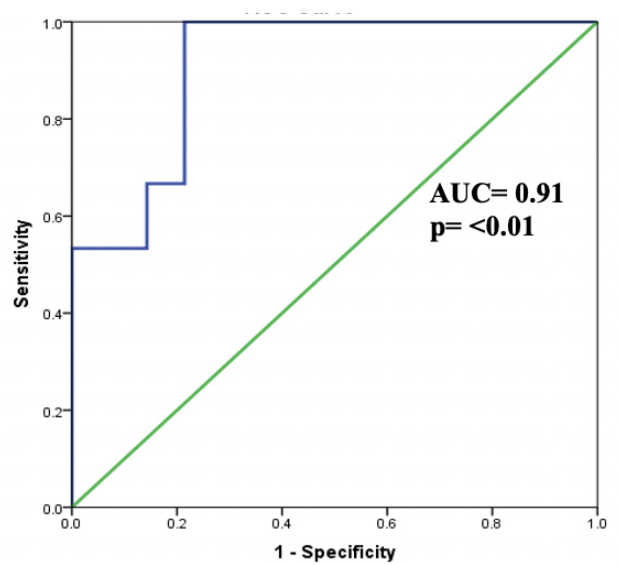

INR

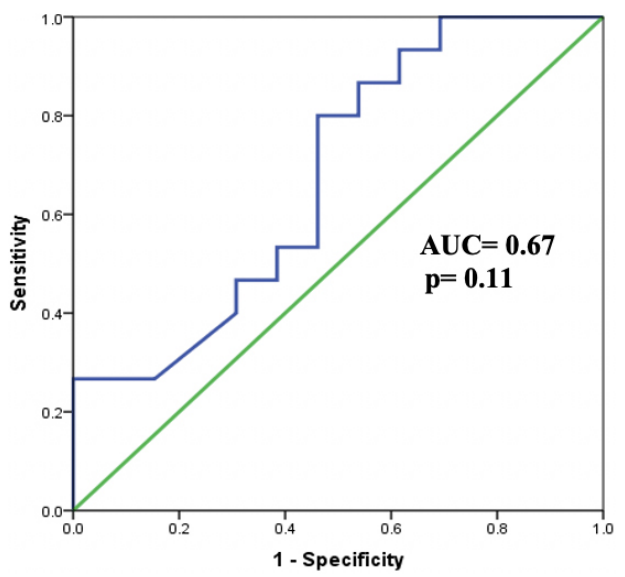

Bilirubin

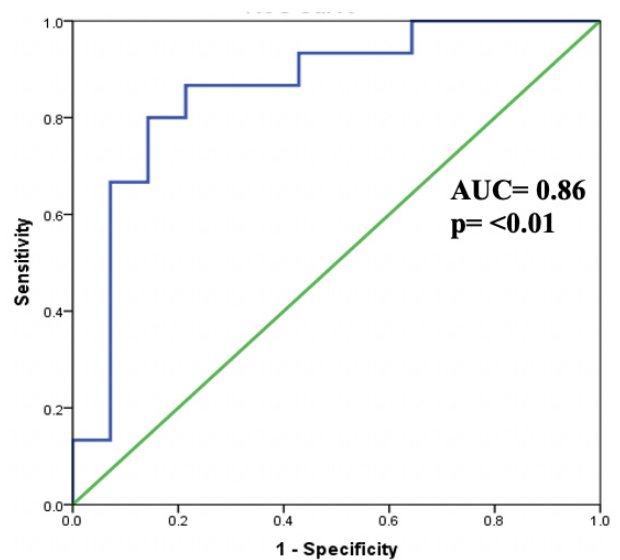

Platelet count

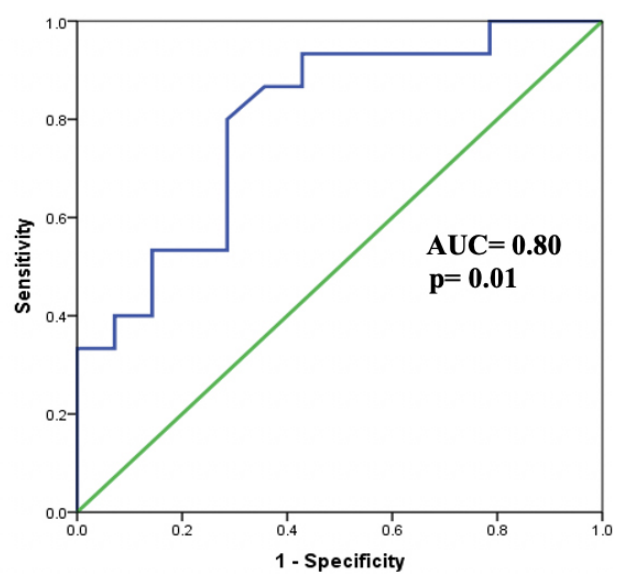

Fig. 2. ROC analysis for LiMAx, total bilirubin, INR and platelet count. Area under the receiver operating characteristic (AUROC) of LiMAx is $0.903 \pm 0.6$ (95\% CI $0.787-1.00, p<0.01)$. A LiMAx value $<177 \mu \mathrm{g} / \mathrm{kg} / \mathrm{h}$ show a sensitivity of $77 \%$ and a specificity of $93 \%$ to detect clinical failure in critically ill patients treated with linezolid. 
statistically significant (Chi-square $=21.367, p<0.01$ ). Nagelkerke $\mathrm{R}$ square statistic showed that $71 \%$ of the variance of clinically cured patients treated with linezolid was predicted from LiMAx-value and the classification table revealed $86 \%$ of subject outcomes predicted correctly. Due to model calibration, the Hosmer and Lemeshow test showed a Chi-square of $3.714(p=0.812)$ suggesting that the model fits the data well.

The ROC and AUROC of LiMAx-value to predict early clinical deterioration were then constructed. The AUROC was 0.903 (96\% CI 0.787-1.00) and the area under the curve was significantly different $(p<0.01)$, which was larger and more predictive than Bilirubin, platelet count and INR. This means that the logistic regression classifies the clinical outcome of the studied patients substantially better than by chance. Regarding the Youden index determination, LiMAx-value $<178 \mu \mathrm{g} / \mathrm{kg} / \mathrm{h}$ gave the best sensitivity (77\%) and specificity (93\%) to predict clinical failure with linezolid therapy (Fig. 2).

\section{Discussion}

The present study investigated the correlation between enzymatic liver function, based on the LiMAx test, linezolid $\mathrm{C}_{\min }$ and clinical outcome in critically ill surgical patients. The results clearly show that severe liver dysfunction leads to clinical failure in the vast majority of patients. There is also evidence that clinical outcome does not primarily depend on the linezolid $\mathrm{C}_{\min }$, but on organ failure. Clinically cured patients showed significantly higher LiMAx values in comparison with those patients who experienced clinical failure. Interestingly, patients with higher LiMAx results presented in 47\% linezolid $\mathrm{C}_{\mathrm{min}}$ below the lower therapeutic range of $2 \mathrm{mg} / \mathrm{L}$. However, these patients showed a better clinical outcome than patients with higher linezolid levels. The impact of linezolid $\mathrm{C}_{\min }$ on patient's outcome is not adequately described in the current literature. Most data investigating linezolid concerning clinical cure found a relationship between the 24-h area under the concentration-time curve to minimum inhibitory concentration (AUC24/MIC) ratio and clinical progress [33-35]. Only Dong and colleagues demonstrated that linezolid $\mathrm{C}_{\min }>2 \mathrm{mg} / \mathrm{L}$ resulted in a bacterial eradication of $>80 \%$. However, the focus of their study was the investigation of linezolid therapy related thrombocytopenia [36]. One possible explanation in our research is the predominantly abdominal site of infection. Intra-abdominal infections are polymicrobial and Enterobacteriaceae, which are gram-negative pathogens, have the main impact on the clinical progression of the infection. Gram-positive bacteria (e.g., Enterococcus spp.) are often involved in nosocomial infections [37]. The results lead to the conclusion that in our patient group linezolid therapy of gram-positive strains was not the primary determinant of clinical outcome, rather than organ failure.

Ide and colleagues showed that patients with preserved renal function revealed lower linezolid $\mathrm{C}_{\min }$ than patients with renal dysfunction or renal replacement therapy $(1.95 \mu \mathrm{g} / \mathrm{ml} \mathrm{vs.} 13.6 \mu \mathrm{g} / \mathrm{ml} \mathrm{vs.} 13.7 \mu \mathrm{g} / \mathrm{ml})$. Although they did not investigate clinical cure in their study, the authors concluded, that a dosing adjustment may be proposed to enhance treatment success [34]. Our findings are in line with these data. We found a significant lower $\mathrm{CL}_{\mathrm{CR}}$ in patients with clinical failure and higher linezolid $\mathrm{C}_{\mathrm{min}}\left(\mathrm{CL}_{\mathrm{CR}}\right.$ $11.5 \mathrm{ml} / \mathrm{min}$ vs. $86.4 \mathrm{ml} / \mathrm{mi} ; 5.1 \mathrm{mg} / \mathrm{L}$ vs. $1.9 \mathrm{mg} / \mathrm{L}$ ).

Several research groups found substantial interindividual variability in the pharmacokinetics of linezolid, particularly in critically ill patients. While most authors described a relationship between linezolid drug levels and renal function, none of the studies investigated the findings systematically due to liver failure $[15,38,39]$. However, non-renal clearance accounts for approximately $65 \%$ of the total clearance of linezolid and the influence of liver function on linezolid pharmacokinetic is highly suspected [40]. In our previous study, we could demonstrate that liver dysfunction, measured by the LiMAx test, explained 30\% 
of the interindividual variability in linezolid clearance. These findings showed precisely the correlation between liver function and linezolid pharmacokinetic [21].

Linezolid therapy is associated with thrombocytopenia and the results of several studies indicated that linezolid-associated thrombocytopenia mainly occurred in patients with higher linezolid $C_{\min }$ [31,41-43]. The mechanism of linezolid-related thrombocytopenia is not well-understood. One hypothesis is a direct toxicity of linezolid toward hematopoietic cells [44]. Since the formation of PNU-142586, one major metabolite of linezolid, is inhibited in severe liver-insufficient patients [45,46], Sasaki and colleagues presume an inhibition of the hepatic metabolism of PNU-142586 and a blocking of active transfer of linezolid to hepatocytes. They concluded that a low linezolid clearance in patients with liver failure causes linezolid accumulation in blood, resulting in a decrease in platelet count [47].

Zhang and colleagues described an elevated risk of linezolid-associated thrombocytopenia in patients with acute-on-chronic liver failure. They concluded that severe liver failure reduces the clearance of linezolid by about 50\%. This leads to an increase of free linezolid in plasma and tissue with a higher risk for developing thrombocytopenia as a toxic side effect [17]. In the present study, patients of the clinical failure group revealed significantly lower platelet counts in comparison with patients of the clinical cure group $(72 / \mathrm{nL}$ vs. $219 / \mathrm{nL}, p=0.001)$. Interestingly, patients with clinical failure demonstrated significantly higher values for lactate $(1.67 \mathrm{mmol} / \mathrm{L}$ vs. $0.67 \mathrm{mmol} / \mathrm{L}, p<0.001)$, total bilirubin $(0.23 \mathrm{mmol} / \mathrm{L}$ vs. $0 \mathrm{mmol} / \mathrm{L}, p=0.003)$, INR (1.39 vs. $1.25, p=0.043)$, MELD score (28 vs. $10, p=0.046$ ) and especially LiMAx $(131 \mu \mathrm{g} / \mathrm{kg} / \mathrm{h}$ vs. $326 \mu \mathrm{g} / \mathrm{kg} / \mathrm{h})$. Further, differences regarding thrombocytopenia between the two groups were also observed at baseline $(103 / \mathrm{nL}$ vs. $254 / \mathrm{nL}, p=0.072)$. In addition to the assumed toxicity of linezolid, these results indicate a relationship between liver failure and thrombocytopenia. Grau and colleagues observed a higher risk to develop anemia and thrombocytopenia in patients on linezolid therapy with lower pre-treatment haematological values [48]. Dong and colleagues showed that lower baseline platelets are related to linezolid-associated thrombocytopenia. They concluded that linezolid $\mathrm{C}_{\min }$ between 2 and $6.3 \mathrm{mg} / \mathrm{L}$ may be the optimal dosage to achieve appropriate efficacy and avoid thrombocytopenia [36]. Linezolid $\mathrm{C}_{\min }$ in the present study revealed mean values $<6.3 \mathrm{mg} / \mathrm{L}$ in the clinical failure group. Despite relatively low linezolid $\mathrm{C}_{\min }$ patients demonstrated low platelet counts. Combined with the remarkable liver dysfunction in this group and low platelets at baseline, one possible explanation is that liver dysfunction was the main determinant for thrombocytopenia. Other authors described the association of chronic liver diseases and linezolid-related thrombocytopenia $[17,49]$. The impact of acute liver failure on platelet count in patients under linezolid therapy is not described so far. In the present study, patients with liver dysfunction developed acute liver failure based on the severity of illness. In many cases, acute liver failure itself leads to thrombocytopenia [50,51]. Our results indicated low platelet counts under linezolid therapy even with mean linezolid $\mathrm{C}_{\min }$ in the normal range. These data indicate a relationship between liver dysfunction and thrombocytopenia under linezolid therapy. Since the LiMAx test is a reliable tool to determine liver function, we can conclude from our results that the influence of linezolid on thrombocytopenia may be overestimated and rather a result of liver failure.

Several studies showed the LiMAx test as a reliable tool to quantify liver dysfunction in different clinical settings including critically ill patients [28,52-54]. In summary, the findings revealed the LiMAx test being superior for predicting liver dysfunction compared to conventional liver function tests (e.g. dynamic indocyanine green test or static tests like bilirubin, INR, lactate etc.). Since the LiMAx test is a new diagnostic tool to measure the dynamic liver function, the costs are significantly higher than those of conventional tests (LiMAx test $€ \mathrm{C} 320=$ approx. \$370). A cost effective study comparing the LiMAx test with standard liver tests, was not conducted so far. There is some evidence that dynamic tests are superior to static tests for assessment of liver function and early and reliable detection of liver dysfunction may lead to an enhanced therapy with a shorter duration of stay in the ICU or hospital [55]. 
There were several limitations to our study. First, the relatively small sample size (a total of 29 patients). Second, the uncontrolled nature of the study may include the risk of bias. Third, the small number of patients did not permit compelling statistical comparisons between groups. Therefore, future prospective studies that include pharmacokinetic analysis will be indispensable for determining the optimal individual linezolid strategy.

\section{Conclusion}

In patients with polymicrobial abdominal infections under linezolid therapy, the LiMAx test, as a marker of organ failure, can predict clinical failure more precisely than linezolid trough levels. Second, the influence of linezolid toxicity may be overestimated concerning thrombocytopenia. In critically ill patients, the impact of liver failure on the development of thrombocytopenia may be more relevant. Further prospective studies, investigating the correlation between linezolid, liver function and clinical outcome with a PK/PD design, are warranted to elucidate this issue.

\section{Acknowledgments}

The authors would like to thank the team of the Surgical Intensive Care Unit of the Charitee for supporting the study. They would also like to thank the team of the "workgroup for the liver" for their cooperation in planning and designing the study.

\section{Conflict of interest}

MS is the inventor of the LiMAx test and has the capital interest in Humedics GmbH (Berlin, Germany), the company marketing the LiMAx test. The remaining authors declared no potential conflicts of interest with respect to the research, authorship, and/or publication of this article.

\section{Funding}

The study was funded by research grants of the Charité University Hospital, Berlin, Germany. No funds were obtained for payment of the authors.

\section{References}

[1] Angus DC, Linde-Zwirble WT, Lidicker J, Clermont G, Carcillo J, Pinsky MR. Epidemiology of severe sepsis in the United States: analysis of incidence, outcome, and associated costs of care. Crit Care Med [Internet]. 2001 Jul; 29(7): 1303-10. Available from: https://insights.ovid.com/pubmed?pmid=11445675.

[2] Engel C, Brunkhorst FM, Bone H-G, Brunkhorst R, Gerlach H, Grond S, et al. Epidemiology of sepsis in Germany: results from a national prospective multicenter study. Intensive Care Med [Internet]. 2007; 33(4): 606-18. Available from: doi: 10.1007/s00134-006-0517-7.

[3] Karlsson S, Varpula M, Ruokonen E, Pettilä V, Parviainen I, Ala-Kokko TI, et al. Incidence, treatment, and outcome of severe sepsis in ICU-treated adults in Finland: the Finnsepsis study. Intensive Care Med [Internet]. 2007 Feb 26 [cited 2018 Jan 8]; 33(3): 435-43. Available from: doi: 10.1007/s00134-006-0504-z. 
[4] Martin CM, Priestap F, Fisher H, Fowler RA, Heyland DK, Keenan SP, et al. A prospective, observational registry of patients with severe sepsis: The Canadian Sepsis Treatment and Response Registry*. Crit Care Med [Internet]. 2009 [cited 2018 Jan 8]; 37(1): 81-8. Available from: https://insights.ovid.com/pubmed?pmid=19050636.

[5] Quenot J-P, Binquet C, Kara F, Martinet O, Ganster F, Navellou J-C, et al. The epidemiology of septic shock in French intensive care units: the prospective multicenter cohort EPISS study. Crit Care [Internet]. 2013 Apr 25 [cited 2018 Jan 8]; 17(2): R65. Available from: http://www.ncbi.nlm.nih.gov/pubmed/23561510.

[6] Álvarez-Lerma F, Palomar Martínez M, Olaechea Astigarraga P, Insausti Ordeñana J, López Pueyo MJ, Gracia Arnillas MP, et al. Analysis of treatments used in infections caused by gram-positive multiresistant cocci in critically ill patients admitted to the ICU. Rev Esp Quimioter [Internet]. 2012 Mar [cited 2018 Jan 8]; 25(1): 65-73. Available from: http://www.ncbi.nlm.nih.gov/pubmed/22488544.

[7] DeRyke CA, Lodise TP, Rybak MJ, McKinnon PS. Epidemiology, treatment, and outcomes of nosocomial bacteremic staphylococcus aureus pneumonia. Chest [Internet]. 2005 Sep 1 [cited 2018 Jan 8]; 128(3): 1414-22. Available from: http://linkinghub.elsevier.com/retrieve/pii/S0012369215521673.

[8] Falagas ME, Siempos II, Vardakas KZ. Linezolid versus glycopeptide or beta-lactam for treatment of Gram-positive bacterial infections: meta-analysis of randomised controlled trials. Lancet Infect Dis [Internet]. 2008 Jan 1 [cited 2018 Jan 8]; 8(1): 53-66. Available from: http://www.ncbi.nlm.nih.gov/pubmed/18156089.

[9] Jiang H, Tang R-N, Wang J. Linezolid versus vancomycin or teicoplanin for nosocomial pneumonia: meta-analysis of randomised controlled trials. Eur J Clin Microbiol Infect Dis [Internet]. 2013 Sep 10 [cited 2018 Jan 8]; 32(9): 1121-8. Available from: doi: 10.1007/s10096-013-1867-z.

[10] McKenzie C. Antibiotic dosing in critical illness. J Antimicrob Chemother. 2011; 66(SUPPL. 2): 25-31.

[11] Cattaneo D, Orlando G, Cozzi V, Cordier L, Baldelli S, Merli S, et al. Linezolid plasma concentrations and occurrence of drug-related haematological toxicity in patients with Gram-positive infections. Int J Antimicrob Agents [Internet]. 2013 Jun 1 [cited 2017 Oct 20]; 41(6): 586-9. Available from: https://ac.els-cdn.com/S0924857913000812/1-s2.0-S09248579 13000812-main.pdf?_tid=47a5b502-f47d-11e7-9d0b-00000aab0f6c\&acdnat=1515420637_f17fdeaacdc0a07903362461a $29 \mathrm{bc} 4 \mathrm{~d} 9$.

[12] Smith PF, Birmingham MC, Noskin GA, Meagher AK, Forrest A, Rayner CR, et al. Safety, efficacy and pharmacokinetics of linezolid for treatment of resistant Gram-positive infections in cancer patients with neutropenia. Ann Oncol. 2003; 14(5): 795-801.

[13] Vinh DC, Rubinstein E. Linezolid: a review of safety and tolerability. J Infect [Internet]. 2009 Sep 1 [cited 2018 Jan 8]; 59: S59-74. Available from: https://www.sciencedirect.com/science/article/pii/S0163445309600098?via\%3Dihub.

[14] Dryden MS. Linezolid pharmacokinetics and pharmacodynamics in clinical treatment [Internet]. Vol. 66, Journal of Antimicrobial Chemotherapy. 2011 [cited 2018 Aug 1]. 7-15. Available from: https://academic.oup.com/jac/articleabstract/66/suppl_4/iv7/729737.

[15] Slatter JG, Stalker DJ, Feenstra KL, Welshman IR, Bruss JB, Sams JP, et al. Pharmacokinetics, metabolism, and excretion of linezolid following an oral dose of [(14)C]linezolid to healthy human subjects. Drug Metab Dispos. 2001; 29(8): 1136-45.

[16] Pea F, Furlanut M, Cojutti P, Cristini F, Zamparini E, Franceschi L, et al. Therapeutic drug monitoring of linezolid: a retrospective monocentric analysis. Antimicrob Agents Chemother [Internet]. 2010 Nov [cited 2018 Jan 9]; 54(11): 4605-10. Available from: http://www.ncbi.nlm.nih.gov/pubmed/20733043.

[17] Zhang YM, Yu W, Zhou N, Li JZ, Xu LC, Xie ZY, et al. High frequency of thrombocytopenia in patients with acute-onchronic liver failure treated with linezolid. Hepatobiliary Pancreat Dis Int. 2015; 14(3): 287-92.

[18] Dailly E, Verdier M-C, Deslandes G, Bouquié R, Tribut O, Bentué-Ferrer D. Level of evidence for therapeutic drug monitoring of ceftriaxone. Therapie [Internet]. 2012 Mar [cited 2018 Jan 9]; 67(2): 145-9. Available from: http://linkinghub. elsevier.com/retrieve/pii/S0040595716308265.

[19] Lheureux O, Trepo E, Hites M, Cotton F, Wolff F, Surin R, et al. Serum $\beta$-lactam concentrations in critically ill patients with cirrhosis: a matched case-control study. Liver Int [Internet]. 2016 Jul 1 [cited 2017 Dec 16]; 36(7): 1002-10. Available from: doi: 10.1111/liv.13039.

[20] Merrell MD, Cherrington NJ. Drug metabolism alterations in nonalcoholic fatty liver disease. Drug Metab Rev [Internet]. 2011 Aug [cited 2018 Jan 9]; 43(3): 317-34. Available from: http://www.ncbi.nlm.nih.gov/pubmed/21612324.

[21] Wicha SG, Frey OR, Roehr AC, Pratschke J, Stockmann M, Alraish R, et al. Linezolid in liver failure: exploring the value of the maximal liver function capacity (LiMAx) test in a pharmacokinetic pilot study. Int J Antimicrob Agents [Internet]. 2017 Oct 1 [cited 2017 Dec 18]; 50(4): 557-63. Available from: https://www.sciencedirect.com/science/article/pii/S0924 857917302728?via\%3Dihub.

[22] Tobin CM, Sunderland J, White LO, MacGowan AP. A simple, isocratic high-performance liquid chromatography assay for linezolid in human serum. J Antimicrob Chemother [Internet]. 2001 Nov 1 [cited 2018 Jan 10]; 48(5): 605-8. Available from: https://academic.oup.com/jac/article-lookup/doi/10.1093/jac/48.5.605.

[23] WA K, EA D, DP W, JE Z. APACHE II: a severity of disease classification system. Crit Care Med [Internet]. 1985 [cited 2020 Dec 29]; 13(10). Available from: https://pubmed.ncbi.nlm.nih.gov/3928249/. 
[24] JL V, R M, J T, S W, A DM, H B, et al. The SOFA (Sepsis-related Organ Failure Assessment) score to describe organ dysfunction/failure. On behalf of the working group on sepsis-related problems of the european society of intensive care medicine. Intensive Care Med [Internet]. 1996 [cited 2020 Dec 29]; 22(7). Available from: https://pubmed.ncbi.nlm.nih. gov/8844239/.

[25] Le Gall J-R, Lemeshow S, Saulnier F. A new simplified acute physiology score (SAPS II) based on a european/north american multicenter study. JAMA J Am Med Assoc [Internet]. 1993 Dec 22 [cited 2020 Dec 29]; 270(24): 2957. Available from: http://jama.jamanetwork.com/article.aspx?doi=10.1001/jama.1993.03510240069035.

[26] Abe S, Yoshihisa A, Takiguchi M, Shimizu T, Nakamura Y, Yamauchi H, et al. Liver dysfunction assessed by model for end-stage liver disease excluding INR (MELD-XI) scoring system predicts adverse prognosis in heart failure. PLoS One [Internet]. 2014 Jun 23; 9(6): e100618-e100618. Available from: https://www.ncbi.nlm.nih.gov/pubmed/24955578.

[27] Fang JT, Tsai MH, Tian YC, Jenq CC, Lin CY, Chen YC, et al. Outcome predictors and new score of critically ill cirrhotic patients with acute renal failure. Nephrol Dial Transplant. 2008.

[28] Kaffarnik MF, Lock JF, Vetter H, Ahmadi N, Lojewski C, Malinowski M, et al. Early diagnosis of sepsis-related hepatic dysfunction and its prognostic impact on survival: a prospective study with the LiMAx test. Crit Care [Internet]. 2013 Oct 31 [cited 2018 Jan 10]; 17(5): R259. Available from: http://www.ncbi.nlm.nih.gov/pubmed/24172237.

[29] Stockmann M, Lock JF, Malinowski M, Niehues SM, Seehofer D, Neuhaus P. The LiMAx test: a new liver function test for predicting postoperative outcome in liver surgery. HPB (Oxford). 2010; 12(2): 139-46.

[30] Montravers P, Dupont H, Bedos J-P, Bret P, Tigecycline Group. Tigecycline use in critically ill patients: a multicentre prospective observational study in the intensive care setting. Intensive Care Med [Internet]. 2014 Jul 29 [cited 2018 Feb 24]; 40(7): 988-97. Available from: http://www.ncbi.nlm.nih.gov/pubmed/24871500.

[31] Moran GJ, Krishnadasan A, Mower WR, Abrahamian FM, LoVecchio F, Steele MT, et al. Effect of cephalexin plus trimethoprim-sulfamethoxazole vs cephalexin alone on clinical cure of uncomplicated cellulitis. JAMA [Internet]. 2017 May 23 [cited 2018 Feb 24]; 317(20): 2088. Available from: http://jama.jamanetwork.com/article.aspx?doi=10.1001/ jama.2017.5653.

[32] Solomkin J, Hershberger E, Miller B, Popejoy M, Friedland I, Steenbergen J, et al. Ceftolozane/tazobactam plus metronidazole for complicated intra-abdominal infections in an era of multidrug resistance: results from a randomized, double-blind, phase 3 trial (ASPECT-cIAI). Clin Infect Dis [Internet]. 2015 May 15 [cited 2018 Feb 24]; 60(10): 1462-71. Available from: http://www.ncbi.nlm.nih.gov/pubmed/25670823.

[33] Dong H, Xie J, Wang T, Chen L, Zeng X, Sun J, et al. Pharmacokinetic/pharmacodynamic evaluation of linezolid for the treatment of staphylococcal infections in critically ill patients. Int J Antimicrob Agents [Internet]. 2016 Sep 1 [cited 2018 Aug 1]; 48(3): 259-64. Available from: https://www.sciencedirect.com/science/article/pii/S0924857916301479?via\%3 Dihub.

[34] Ide T, Takesue Y, Ikawa K, Morikawa N, Ueda T, Takahashi Y, et al. Population pharmacokinetics/pharmacodynamics of linezolid in sepsis patients with and without continuous renal replacement therapy. Int J Antimicrob Agents [Internet]. 2018 May 1 [cited 2018 Aug 1]; 51(5): 745-51. Available from: https://www.sciencedirect.com/science/article/pii/ S0924857918300323?via\%3Dihub.

[35] Rayner CR, Forrest A, Meagher AK, Birmingham MC, Schentag JJ. Clinical pharmacodynamics of linezolid in seriously ill patients treated in a compassionate use programme. Clin Pharmacokinet [Internet]. 2003 [cited 2018 Aug 1]; 42(15): 1411-23. Available from: https://link.springer.com/content/pdf/10.2165\%2F00003088-200342150-00007.pdf.

[36] Dong HY, Xie J, Chen LH, Wang TT, Zhao YR, Dong YL. Therapeutic drug monitoring and receiver operating characteristic curve prediction may reduce the development of linezolid-associated thrombocytopenia in critically ill patients. Eur J Clin Microbiol Infect Dis [Internet]. 2014 [cited 2018 Aug 1]; 33(6): 1029-35. Available from: https://link. springer.com/content/pdf/10.1007\%2Fs10096-013-2041-3.pdf.

[37] Ballus J, Lopez-Delgado JC, Sabater-Riera J, Perez-Fernandez XL, Betbese AJ, Roncal JA. Surgical site infection in critically ill patients with secondary and tertiary peritonitis: epidemiology, microbiology and influence in outcomes. BMC Infect Dis [Internet]. 2015 [cited 2018 Aug 1]; 15(1). Available from: https://bmcinfectdis.biomedcentral.com/track/pdf/ 10.1186/s12879-015-1050-5.

[38] Swoboda S, Ober MC, Lichtenstern C, Saleh S, Schwenger V, Sonntag HG, et al. Pharmacokinetics of linezolid in septic patients with and without extended dialysis. Eur J Clin Pharmacol. 2010; 66(3): 291-8.

[39] Zoller M, Maier B, Hornuss C, Neugebauer C, Döbbeler G, Nagel D, et al. Variability of linezolid concentrations after standard dosing in critically ill patients: a prospective observational study. Crit Care [Internet]. 2014 Jul 10 [cited 2018 Jan 9]; 18(4): R148. Available from: http://ccforum.biomedcentral.com/articles/10.1186/cc13984.

[40] MacGowan AP. Pharmacokinetic and pharmacodynamic profile of linezolid in healthy volunteers and patients with Gram-positive infections. J Antimicrob Chemother [Internet]. 2003 [cited 2018 Aug 1]; 51(90002): 17ii-25. Available from: https://academic.oup.com/jac/article-abstract/51/suppl_2/ii17/2473475.

[41] Boak LM, Rayner CR, Grayson ML, Paterson DL, Spelman D, Khumra S, et al. Clinical population pharmacokinetics and toxicodynamics of linezolid. Antimicrob Agents Chemother [Internet]. 2014 [cited 2018 Aug 1]; 58(4): 2334-43. Available from: http://aac.asm.org/. 
[42] Lopez-Garcia B, Luque S, Roberts JA, Grau S. Pharmacokinetics and preliminary safety of high dose linezolid for the treatment of Gram-positive bacterial infections [Internet]. Vol. 71, Journal of Infection. W.B. Saunders; 2015 [cited 2018 Aug 1]. 604-7. Available from: https://www.sciencedirect.com/science/article/pii/S0163445315002029?via\%3Dihub.

[43] Pea F, Viale P, Cojutti P, Del pin B, Zamparini E, Furlanut M. Therapeutic drug monitoring may improve safety outcomes of long-term treatment with linezolid in adult patients. J Antimicrob Chemother [Internet]. 2012 [cited 2018 Aug 1]; 67(8): 2034-42. Available from: https://academic.oup.com/jac/article-abstract/67/8/2034/748220.

[44] Green SL, Maddox JC, Huttenbach ED. Linezolid and reversible myelosuppression [Internet]. Vol. 285, Journal of the American Medical Association. American Medical Association; 2001 [cited 2018 Aug 1]. 1291. Available from: http://jama.jamanetwork.com/article.aspx?doi=10.1001/jama.285.10.1291.

[45] Diamond DL, Jacobs JM, Paeper B, Proll SC, Gritsenko MA, Carithers RL, et al. Proteomic profiling of human liver biopsies: Hepatitis $C$ virus-induced fibrosis and mitochondrial dysfunction. Hepatology [Internet]. 2007 Sep 1 [cited 2018 Aug 1]; 46(3): 649-57. Available from: doi: 10.1002/hep.21751.

[46] Wynalda M, Hauer M, Wienkers L. Oxidation of the Novel Oxazolidinone Antibiotic Linezolid in Human Liver Microsomes [Internet]. 2000 [cited 2018 Aug 6]. Available from: http://dmd.aspetjournals.org/content/dmd/28/9/1014.full.pdf.

[47] Sasaki T, Takane H, Ogawa K, Isagawa S, Hirota T, Higuchi S, et al. Population pharmacokinetic and pharmacodynamic analysis of linezolid and a hematologic side effect, thrombocytopenia, in Japanese patients. Antimicrob Agents Chemother [Internet]. 2011 [cited 2018 Aug 6]; 55(5): 1867-73. Available from: http://aac.asm.org/.

[48] Grau S, Morales-Molina JA, Mateu-de Antonio J, Marín-Casino M, Alvarez-Lerma F. Linezolid: Low pre-treatment platelet values could increase the risk of thrombocytopenia [8] [Internet]. Vol. 56, Journal of Antimicrobial Chemotherapy. 2005 [cited 2018 Aug 6]. 440-1. Available from: https://watermark.silverchair.com/dki202.pdf?token=AQECAHi208BE49 Ooan9kkhW_Ercy7Dm3ZL_9Cf3qfKAc485ysgAAAZ0wggGZBgkqhkiG9w0BBwagggGKMIIBhgIBADCCAX8GCSq GSIb3DQEHATAeBglghkgBZQMEAS4wEQQMLn0QGhaV8NCPsrVlAgEQgIIBUCYzf5oMLd9aFTcMMG0Zg4bbdG 0xAR5UIZDrP_YRFDpxZ2An.

[49] Ikuta SI, Tanimura K, Yasui C, Aihara T, Yoshie H, Iida H, et al. Chronic liver disease increases the risk of linezolidrelated thrombocytopenia in methicillin-resistant Staphylococcus aureus-infected patients after digestive surgery. J Infect Chemother [Internet]. 2011 Jun 1 [cited 2018 Aug 6]; 17(3): 388-91. Available from: http://www.ncbi.nlm.nih.gov/pubmed/ 21161560

[50] Munoz SJ, Stravitz RT, Gabriel DA. Coagulopathy of Acute Liver Failure [Internet]. Vol. 13, Clinics in Liver Disease. Elsevier; 2009 [cited 2018 Aug 6]. 95-107. Available from: https://www.sciencedirect.com/science/article/pii/S108932610800 1128?via\%3Dihub.

[51] Pluta A, Gutkowski K, Hartleb M. Coagulopathy in liver diseases [Internet]. Vol. 55, Advances in Medical Sciences. Elsevier; 2010 [cited 2018 Aug 6]. 16-21. Available from: https://www.sciencedirect.com/science/article/pii/S18961126 $1460002 X$ ?via\%3Dihub.

[52] Jara M, Bednarsch J, Malinowski M, Pratschke J, Stockmann M. Effects of oxaliplatin-based chemotherapy on liver function - an analysis of impact and functional recovery using the LiMAx test. Langenbeck's Arch Surg [Internet]. 2016 Feb 27 [cited 2018 Aug 6]; 401(1): 33-41. Available from: http://link.springer.com/10.1007/s00423-015-1352-5.

[53] Kaffarnik M, Stoeger G, Liebich J, Grieser C, Pratschke J, Stockmann M. Liver function, quantified by LiMAx test, after major abdominal surgery. comparison between open and laparoscopic approach. World J Surg [Internet]. 2018 Feb 24 [cited 2018 Jan 10]; 42(2): 557-66. Available from: http://link.springer.com/10.1007/s00268-017-4170-9.

[54] Stockmann M, Lock JF. Prediction of Postoperative Outcome After Hepatectomy With a New Bedside Test for Maximal Liver Function Capacity. 2009; 250(1): 119-25.

[55] Sakka SG. Assessing liver function [Internet]. Vol. 13, Current Opinion in Critical Care. 2007 [cited 2018 Aug 6]. 207-14. Available from: https://insights.ovid.com/crossref?an=00075198-200704000-00016. 